\title{
Kinerja Marshall Immersion pada Campuran Asphalt Concrete Wearing Course (AC-WC) dengan Penambahan Cangkang Sawit sebagai Substitusi Agregat Halus
}

\author{
Mukhlis $^{1)}$, Lusyana2), Enita Suardi3), Fauna Adibroto ${ }^{4)}$ \\ 1), 2), 3), 4), Staf Pengajar Jurusan Teknik Sipil Politeknik Negeri Padang,Kampus Limau Manis \\ Email : palito alam@yahoo.com
}

\begin{abstract}
Asphalt concrete wearing courses (AC-WC) are asphalt mixtures which consist of coarse and fine aggregates plus fillers which have a continuous gradation with asphalt binder. In general, the aggregates in the AC WC mixtures consist of natural rock materials which are broken down and in certain areas the availability is limited so it must be imported from other regions. This resulted in relatively high prices from the asphalt mixture. This can be anticipated by looking for alternative aggregate substitute materials, one alternative is to use palm oil shells.

In this test, palm shells were used as a substitute for fine aggregates with variations in percentage of palm shells, namely $0 \%, 5 \%, 10 \%, 15 \%, 20 \%, 25 \%$, the tests were carried out namely the testing of volumetric characteristics, Marshall characteristics, determination of optimum asphalt content and Marshall immersion. From the results of the study obtained the value of Marshall Immersion decreases as the percentage of palm shells increases in the mixture.
\end{abstract}

Keywords : palm oil shells, optimum asphalt content, marshall immersion

\section{PENDAHULUAN}

Asphalt Concrete Wearing Course (AC WC) adalah campuran beraspal yang terdiri dari agregat kasar dan agregat halus ditambah filler yang mempunyai gradasi menerus dengan bahan pengikat aspal. Pada umumnya agregat pada campuran $A C W C$ ini terdiri dari bahan batuan alam yang dipecah dan pada daerah tertentu ketersediaannya terbatas sehingga harus didatangkan dari daerah lain. Hal ini mengakibatkan relatif tingginya harga dari campuran beraspal tersebut. Sumatera Barat adalah merupakan daerah yang memiliki lahan pertanian dan perkebunan yang luas. Salah satunya adalah berupa perkebunan kelapa sawit yang menghasilkan minyak sawit dengan limbah berupa cangkang sawit. Limbah cangkang sawit ini mudah dan murah didapat dan merupakan limbah yang cukup besar. Agar pemanfaatan limbah yang dihasilkan dari pengolahan kelapa sawit tersebut (cangkang sawit) dapat dilakukan semaksimal mungkin, maka salah satunya adalah digunakan sebagai pengganti sebagian agregat halus dalam suatu campuran beraspal.

Berdasarkan penelitian terdahulu yang sudah dilaksanakan di dapat hasil sebagai berikut, Latif suparma, 2014, "Potensi pengunaan Limbah Kelapa Sawit Sebagai agregat pengisi pada Campuran HRS-Base ", Jurnal Transportasi, Volume 14 Nomor 2, Agustus 2014, hal 87-89 . Hasil perancangan laboratorium dengan metode Marshall untuk campuran HRS-Base dengan mengunakan agregat pengisi abu serat kelapa sawit dan abu cangkang sawit secara umum menunjukan semakin besan kadungan abu kelapa sawit semakin besar kebutuhan akan aspal. Hasil uji kateristik campuran 
menunjukan bahwa campuran menunjukan campuran HRS-Base menggunakan agregat pengisi abu serat kelapa sawit dan abu cangkang sawit berpotensi tahan terhadap deformasi namun kurang tahan terhadap retak dan tarik.

Tunggul Wijaya Panggabean (2012), Perancangan Laboratorium Pemanfaatan Abu Cakang Kelapa Sawit Sebagai Filler Pada Campuran HRS - BC, mempunyai IRS > $90 \%$, ini menandakan campuran ini tahan terhadap air dan perubahan temperatur. Campuran HRS-Base dengan filler Abu Cakang Kelapa Sawit mempunyai TSR yang memenuhi syarat (> 80\%) adalah pada variasi $25 \%$ filler abu cakang sawit (82\%). Hal ini menandakan bahwa pada variasi $25 \%$ filler abu cakang sawit, campuran masih memenuhi minimum kuat tarik tak langsung.

Muhammad, Hariadi (2015) " Penggunaan Limbah Cangkang Kelapa Sawit Sebagai Aggregat Kasar Pada Perkerasan Lentur Jalan Raya (Hrs-Wc)" . Diploma Thesis, Universitas Andalas. Dari penelitian ini didapat bahwa dengan menggunakan cangkang kelapa sawit sebagai pengganti agregat kasar sebanyak $30 \%$ dari total agregat mempunyai stabilitas yang cukup tinggi yaitu $869,67 \mathrm{~kg}$, kelelehan, 3,45 mm, MQ, 256,33 kg/mm, danVIM, 5,88\%. Dan dari pengujian wheel tracking didapatkan stabilitas dinamis adalah 2217,647 lintasan/mm dan deformasi adalah 2,643 mm lebih tinggi $28,43 \%$ dibandingkan dengan variasi campuran $50 \%$ cangkang kelapa sawit. Sehingga disarankan campuran dengan kadar cangkang kelapa sawit 30\% dari agregat kasar tersebut dapat digunakan sebagai campuran perkerasan jalan raya. $\begin{array}{cccc}\text { Mukhlis } & \text { dkk } & \text { (2015),Pengaruh } \\ \text { Modifikasi Aspal Dengan } & \text { Abu Cangkang }\end{array}$ Sawit Terhadap Kinerja Campuran Beton Aspal Lapis Aus (AC-WC). Proseding Seminar Nasional Jurusan Teknik Sipil Politeknik Negeri Jakarta, Volume 90, 5 Desember 2015. Hasil penelitian menunjukkan bahwa penambahan abu cangkang sawit terhadap bahan pengikat aspal menyebabkan perubahan pada karakteristik aspal, dimana aspal menjadi lebih keras dan kurang peka terhadap suhu seiring dengan meningkatnya penambahan abu cangkang sawit terhadap aspal dan hal ini dapat dilihat pada nilai penetrasi dan indeks penetrasi. Kinerja campuran menunjukkan bahwa penambahan aspal modifikasi menyebabkan stabilitas cenderung naik sampai melewati titik maksimal yaitu pada campuran dengan aspal modifikasi AM-2,5 yang kemudian kembali menurun sedangkan pada durabilitas cenderung menurun, dimana Indeks Kekuatan Marshall Sisa (IKS) yang paling kecil terdapat pada campuran dengan aspal modifikasi AM10.Kinerja campuran menunjukkan hasil yang baik yaitu pada campuran dengan aspal modifikasi AM-2,5, dimana hal ini dapat dilihat pada Hasil Analisis Marshall dan Perendaman Marshall.

\section{METODE PENELITIAN}

Pada penelitian terdiri dari penelitian laboratorium, untuk penelitian laboratorium dilakukan pengujian material agregat, cangkang kelapa sawit, aspal, dan marshall. Metoda yang dipakai yaitu metoda komperatif yang membandingkan hasil dari pengujian Marshall terhadap persentase campuran cangkang sawit. 


\subsection{Lokasi Penelitian}

Penelitian ini akan dilaksanakan di Laboratorium Jurusan Teknik Sipil

Politeknik Negeri Padang.

\subsection{Alat - Alat}

- Satu Set Saringan

- Alat Uji Pemeriksaan Aspal

- Alat Uji Pemeriksaan Agregat

- Alat Uji Karakteristik Campuran Aspal

- Alat Bantu

\subsection{Bahan Penelitian}

1) Agregat Halus

Berasal dari stone crusher PT. ATR By Pass, Kota Padang.
2) Agregat Kasar

Berasal dari stone crusher PT. ATR

By Pass, Kota Padang.

3) Cangkang Kelapa Sawit

Berasal dari PT. Sawit Jujungan Abadi., Kab. Bungo, Sumatera Barat.

4) Filler

Berasal dari stone crusher PT. ATR By Pass, Kota Padang.

5) Aspal

Berasal dari PT. Pertamina.

\subsection{Diagram Alir Penelitian}

Jalannya penelitian ini mengikuti bentuk diagram alir seperti gambar berikut :

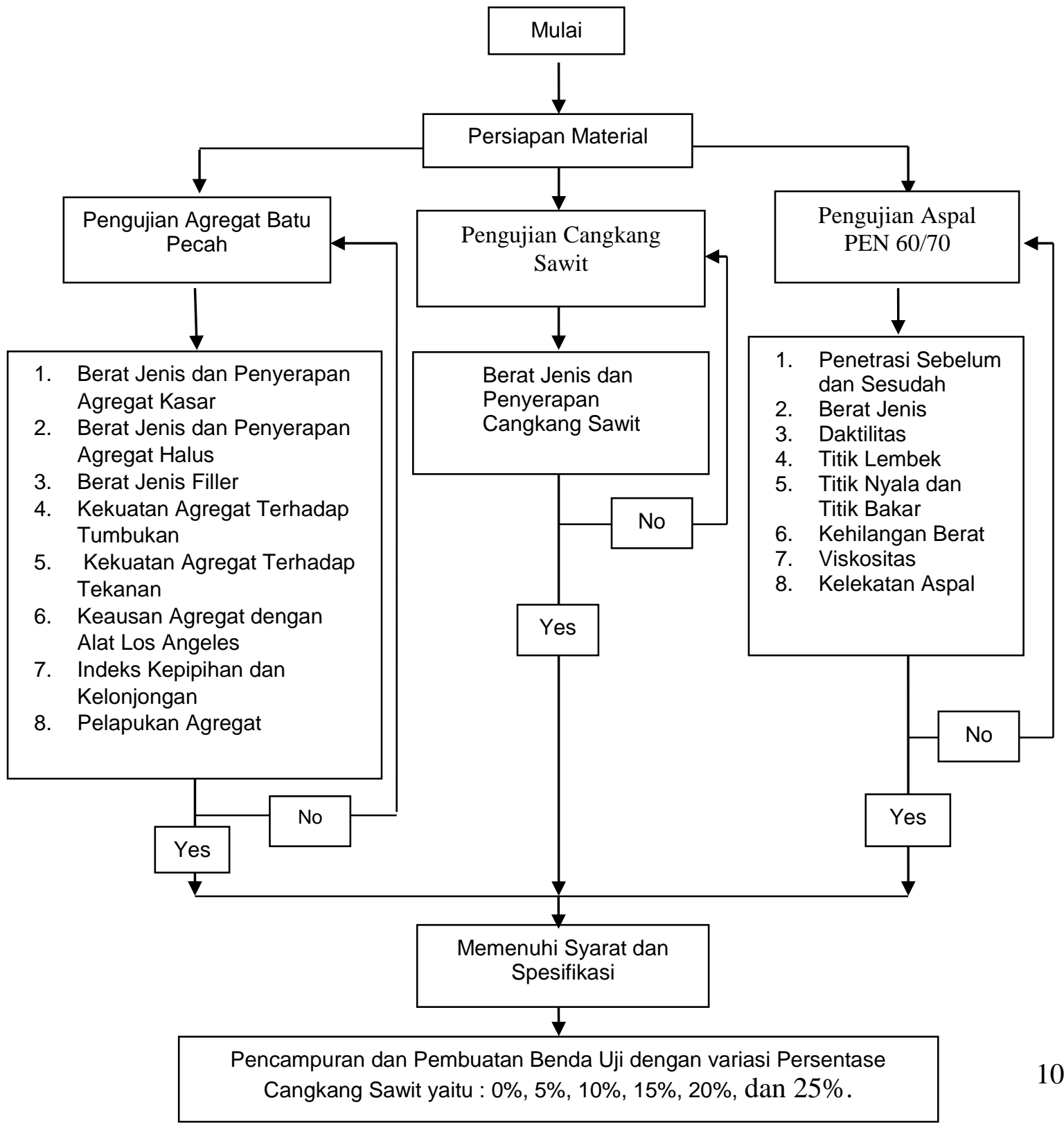




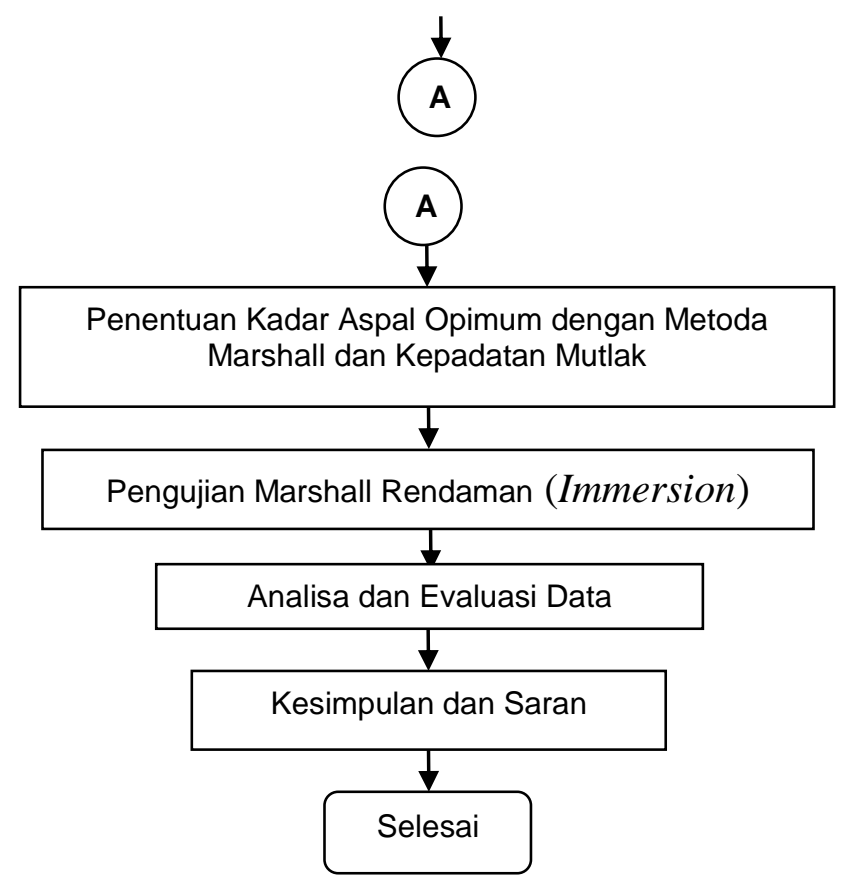

Gambar 1. Diagram Alir Penelitian

\section{HASIL DAN PEMBAHASAN}

Hasil Pemeriksaan Agregat, Aspal pen 60/70, dan Cangkang

Tabel 1 sampai dengan Tabel 4 berikut menunjukan hasil pengujian karakteristik agregat dan Cangkang. Tabel 5 menunjukan hasil pengujian Aspal Pen 60/70

Tabel 1. Hasil Pengujian Agregat Kasar

\begin{tabular}{|c|c|c|}
\hline $\begin{array}{l}\mathbf{N} \\
\mathbf{0}\end{array}$ & Karakteristik & Hasil \\
\hline \multicolumn{3}{|c|}{ 1. Berat Jenis Bulk } \\
\hline & a. $\quad$ Saringan $12,5 \mathrm{~mm} ; \mathrm{gr} / \mathrm{cc}$ & 2,600 \\
\hline & b. Saringan $9,5 \mathrm{~mm} ; \mathrm{gr} / \mathrm{cc}$ & 2,491 \\
\hline & c. Saringan $4,75 \mathrm{~mm} ; \mathrm{gr} / \mathrm{cc}$ & 2,451 \\
\hline \multicolumn{3}{|c|}{ 2. $\quad$ Berat Jenis SSD } \\
\hline & a. Saringan $12,5 \mathrm{~mm} ; \mathrm{gr} / \mathrm{cc}$ & 2,653 \\
\hline & b. Saringan $9,5 \mathrm{~mm} ; \mathrm{gr} / \mathrm{cc}$ & 2,550 \\
\hline & c. Saringan $4,75 \mathrm{~mm} ; \mathrm{gr} / \mathrm{cc}$ & 2,525 \\
\hline \multicolumn{3}{|c|}{ 3. $\quad$ Berat Jenis Semu } \\
\hline & a. $\quad$ Saringan $12,5 \mathrm{~mm} ; \mathrm{gr} / \mathrm{cc}$ & 2,746 \\
\hline & b. $\quad$ Saringan $9,5 \mathrm{~mm} ; \mathrm{gr} / \mathrm{cc}$ & 2,647 \\
\hline
\end{tabular}

\begin{tabular}{lll}
\hline & c. Saringan 4,75 mm ; gr/cc & 2,645 \\
\hline 4. & Los Angeles ; \% & 26,18 \\
\hline 5. & AIV (Agregate Impact Value) ; \% & 14,30 \\
\hline 6. & ACV (Agregate Crushing Value) $;$ & 21,58 \\
& $\%$
\end{tabular}

Tabel 2. Hasil Pengujian Agregat Halus

\begin{tabular}{|c|c|c|}
\hline No & Karakteristik & Hasil \\
\hline \multicolumn{3}{|c|}{ 1. Berat Jenis Bulk } \\
\hline & a. $\quad$ Saringan $2,36 \mathrm{~mm} ; \mathrm{gr} / \mathrm{cc}$ & 2,393 \\
\hline & b. Saringan $1,18 \mathrm{~mm} ; \mathrm{gr} / \mathrm{cc}$ & 2,326 \\
\hline & c. Saringan $0,6 \mathrm{~mm} ; \mathrm{gr} / \mathrm{cc}$ & 2,598 \\
\hline & d. Saringan 0,3 mm; gr/cc & 2,567 \\
\hline & e. $\quad$ Saringan $0,15 \mathrm{~mm} ; \mathrm{gr} / \mathrm{cc}$ & 2,639 \\
\hline & f. Saringan $0,075 \mathrm{~mm} ; \mathrm{gr} / \mathrm{cc}$ & 2,585 \\
\hline \multicolumn{3}{|c|}{ 2. $\quad$ Berat Jenis SSD } \\
\hline & a. Saringan $2,36 \mathrm{~mm} ; \mathrm{gr} / \mathrm{cc}$ & 2,496 \\
\hline & b. Saringan $1,18 \mathrm{~mm} ; \mathrm{gr} / \mathrm{cc}$ & 2,424 \\
\hline & c. Saringan $0,6 \mathrm{~mm} ; \mathrm{gr} / \mathrm{cc}$ & 2,660 \\
\hline & d. Saringan $0,3 \mathrm{~mm} ; t / \mathrm{m}^{3}$ & 2,567 \\
\hline & e. Saringan $0,15 \mathrm{~mm} ; \mathrm{gr} / \mathrm{cc}$ & 2,639 \\
\hline & f. $\quad$ Saringan $0,075 \mathrm{~mm} ; \mathrm{gr} / \mathrm{cc}$ & 2,585 \\
\hline
\end{tabular}




\begin{tabular}{cll}
\hline a. & Saringan $2,36 \mathrm{~mm} ; \mathrm{gr} / \mathrm{cc}$ & 2,667 \\
\hline b. & Saringan $1,18 \mathrm{~mm} ; \mathrm{gr} / \mathrm{cc}$ & 2,577 \\
\hline c. & Saringan $0,6 \mathrm{~mm} ; \mathrm{gr} / \mathrm{cc}$ & 2,769 \\
\hline d. & Saringan $0,3 \mathrm{~mm} ; \mathrm{gr} / \mathrm{cc}$ & 2,567 \\
\hline e. & Saringan $0,15 \mathrm{~mm} ; \mathrm{gr} / \mathrm{cc}$ & 2,639 \\
\hline f. & Saringan $0,075 \mathrm{~mm} ; \mathrm{gr} / \mathrm{cc}$ & 2,585
\end{tabular}

Tabel 3. Hasil Pengujian Filler

\begin{tabular}{rrr}
\hline No & Karakteristik & Hasil \\
\hline 1. & Berat Jenis $; \mathrm{t} / \mathrm{m}^{3}$ & 2,609 \\
\hline
\end{tabular}

Tabel 4. Hasil Pengujian Cangkang Kelapa Sawit

\begin{tabular}{|l|l|l|}
\hline No & \multicolumn{1}{|c|}{ Karakteristik } & Hasil \\
\hline 1. & Berat Jenis & \\
\hline & a. Saringan $2,36 \mathrm{~mm} ; t / \mathrm{m}^{3}$ & 1,112 \\
\hline & b. Saringan $1,18 \mathrm{~mm} ; \mathrm{t} / \mathrm{m}^{3}$ & 1,112 \\
\hline 2. & Los Angeles ; \% & 3,3 \\
\hline 3. & AIV (Agregat Impact Value) ; \% & 4,83 \\
\hline 4. & $\begin{array}{l}\text { ACV (Agregat Crushing Value) } ; \\
\%\end{array}$ & 3,24 \\
\hline
\end{tabular}

Sumber: Hasil Pengujian dan perhitungan Lab. Material Jalan Politeknik Negeri Padang

Hasil yang diperoleh menunjukan bahwa agregat yang digunakan telah memnuhi spesifikasi yang disyaratkan Bina Marga 2010 Revisi 3 Divisi 6.

Tabel 5. Hasil Pengujian Aspal

\begin{tabular}{|c|l|c|}
\hline No & \multicolumn{1}{|c|}{ Karakteristik } & Hasil \\
\hline 1. & Berat Jenis ; $/ \mathrm{m}^{3}$ & 1,045 \\
\hline 2. & Penetrasi ; mm & 60 \\
\hline 3. & Daktilitas ; cm & 130 \\
\hline 4. & ${\text { Titik Lembek ; }{ }^{\circ} \mathrm{C}}^{3}$ & 48 \\
\hline 5. & Titik Nyala dan Titik Bakar ; & $310 \& 318$ \\
\hline
\end{tabular}

\begin{tabular}{|c|l|c|}
\hline & ${ }^{\circ} \mathrm{C}$ & \\
\hline 6. & Viskositas ; $\mathrm{cm}^{2} /$ detik & 148 dan \\
& & 156 \\
\hline 7. & Kehilangan Berat ; \% & 0,235 \\
\hline \multicolumn{2}{|l|}{ Sumber: Hasil Pengujian dan perhitungan Lab. Material }
\end{tabular}
Jalan Politeknik Negeri Padang

Hasil yang diperoleh menunjukan bahwa aspal pen 60/70 yang digunakan telah memenuhi spesifikasi yang disyaratkan Bina Marga 2010 Revisi 3 Divisi 6.

\section{Hasil Kadar Aspal Optimum}

Pada Tabel 6 menunjukan pada persentase cangkang kelapa sawit $0 \%$ memiliki nilai $\mathrm{KAO}$ 5,85; cangkang kelapa sawit $5 \%$ memiliki nilai KAO 6,4; cangkang kelapa sawit $10 \%$ memiliki nilai $\mathrm{KAO} 6,55$; cangkang kelapa sawit $15 \%$ memiliki nilai $\mathrm{KAO}$ 6,75 . Data kadar aspal optimum yang diperoleh menunjukan bahwa akibat dari penambahan cangkang kelapa sawit nilai kadar aspal optimum bertambah. Hal ini terjadi karena pada campuran dengan cangkang kelapa sawit sebagai pengganti agregat halus dalam memenuhi persyaratan karakteristik volumetrik campuran dan karakteristik marshall membutuhkan kadar aspal yang lebih tinggi. Hal ini juga disebabkan karena berat jenis dari cangkang kelapa sawit yang lebih kecil dibanding berat jenis agregat halus, sehingga campuran beraspal membutuhkan kadar aspal yang lebih tinggi.

Tabel 6. Hasil Analisa Marshall Pada Benda Uji Kondisi KAO

\begin{tabular}{cccccccc}
\hline $\begin{array}{c}\text { Sifat - Sifat } \\
\text { Campuran }\end{array}$ & $\mathbf{0 \%}$ & $\mathbf{5 \%}$ & $\mathbf{1 0 \%}$ & $\mathbf{1 5 \%}$ & $\mathbf{2 0 \%}$ & $\mathbf{2 5 \%}$ & $\begin{array}{c}\text { Spesifika } \\
\text { si }\end{array}$ \\
\hline $\begin{array}{c}\text { Kadar Aspal } \\
\text { Optimum; \% }\end{array}$ & 5,85 & 6,4 & 6,55 & 6,75 & - & - & \\
\hline Kepadatan; $t / m^{3}$ & 2,253 & 2,205 & 2,182 & 2,144 & & $3-5$ \\
\hline VIM; \% & 4,64 & 4,02 & 4,42 & 4,53 & & \\
\hline
\end{tabular}




\begin{tabular}{cccccc}
\hline VMA; \% & 15,14 & 15,47 & 15,02 & 15,09 & $\geq 15$ \\
\hline VFA; \% & 69,65 & 74,17 & 70,67 & 69,90 & $\geq 65$ \\
\hline Stabilitas; kg & 1548,26 & 1626,46 & 1332,47 & 1196,01 & $\geq 800$ \\
\hline Kelelehan; mm & 5,23 & 3,18 & 4,78 & 3,19 & $\geq 3$ \\
\hline $\begin{array}{c}\text { Marshall Quotient; } \\
\text { (kg/mm) }\end{array}$ & 327,28 & 512,53 & 280,84 & 375,65 & $\geq 250$ \\
\hline
\end{tabular}

\section{Analisis Pengujian Perendaman Marshall}

Pengujian perendaman marshall (marshall immersion) merupakan pengujian untuk mengetahui durabilitas campuran beraspal. Dalam pengujian ini, campuran diukur kinerja ketahanannya pada air panas dengan temperatur $60^{\circ} \mathrm{C}$ selama 30 menit dan 24 jam. Hal ini mengidentifikasikan bahwa campuran tersebut cukup rentan terhadap pengaruh air dan temperatur. Nilai ini dinyatakan dengan nilai stabilitas sisa yang menunjukan perilaku kelekatan antar butir - butir agregat dengan aspal didalam campuran. Berdasarkan hasil penelitian campuran beraspal setelah perendaman mengalami penurunan stabilitas, dimana stabilitas setelah perendaman cenderung menurun seiring dengan penambahan cangkang kelapa sawit.

Dari Gambar 2 dapat dilihat bahwa indeks kekuatan sisa tertinggi terdapat pada campuran $0 \%$ dengan nilai $80,12 \%$ dan nilai terendahnya pada campuran $15 \%$ yaitu $76,52 \%$. Hasil ini secara keseluruhan menunjukan bahwa dengan penambahan cangkang sawit campuran tersebut masih memenuhi persyaratan minimum yaitu $75 \%$.

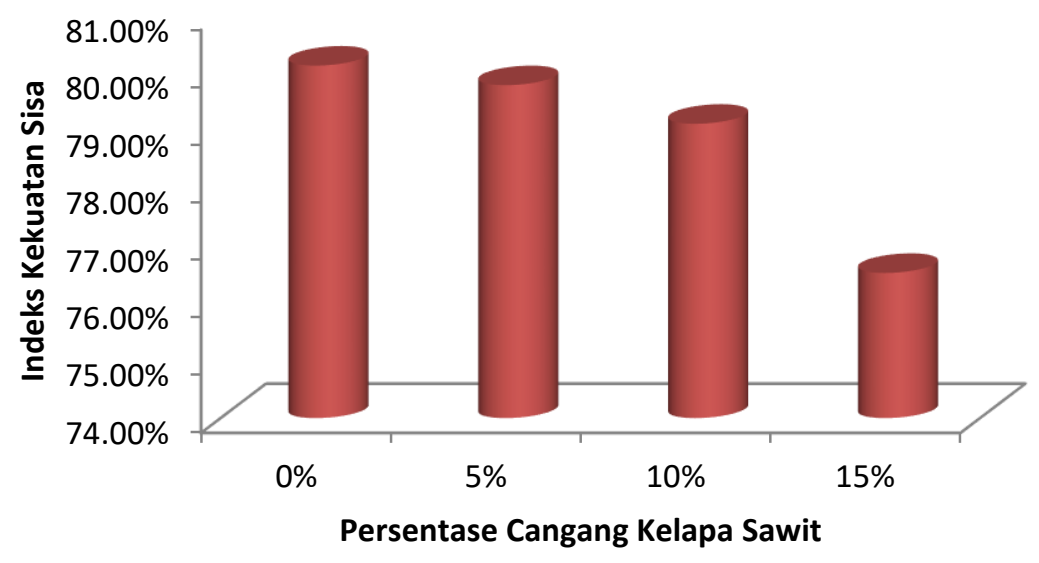

Gambar 2. Perbandingan Indeks Kekuatan Sisa

\section{KESIMPULAN}

1. Dari hasil pengujian diketahui bahwa dengan penambahan kadar cangkang sawit sebagai pengganti agregat halus pada campuran AC - WC akan meningkatkan kadar aspal optimum (KAO).
2. Dari hasil penelitian diperoleh nilai Marshall Immersion cenderung menurun seiring bertambahnya cangkang sawit, campuran dengan cangkang sawit 5\% memberikan kinerja yang lebih baik dibanding dengan cangkang sawit (10\%, 15\%, 20\% dan $25 \%$ ), ini ditunjukan dengan hasil indeks kekuatan 
sisa yang lebih tinggi $(79,78 \%)$ disbanding dengan campuran dengan cangkkang sawit lainnya.

\section{UCAPAN TERIMA KASIH}

Penelitian ini bisa dilaksanakan atas pembiayaan Dana DIPA politeknik Negeri Padang Tahun 2018.

\section{DAFTAR PUSTAKA}

Silvia Sukirman, 2003, Beton Aspal Campuran Panas, Yayasan Obor Indonesia.

Carlina, Serli, 2013, Pengaruh Variasi Temperatur Pemadatan Terhadap Nilai Stabilitas Marshall Pada Laston $A C-W C$,

F. Elsa Putra, 2003, Penggunaan Cangkang Sawit sebagai Campuran Beton, Lab. Material dan Struktur, FT .Universitas Andalas, Sumatera Barat.

Sherly L. Hendarsin, 2000, Penuntun Praktis Perencanaan Teknik Jalan Raya, Bandung, Politeknik Negeri Bandung.

Mukhlis dkk, 2015, Pengaruh Modifikasi Aspal dengan Abu Cangkang Sawit Terhadap Kinerja CampuranBeton Aspal Lapis Aus (Ac-Wc),Padang, Politeknik Negeri Padang.

Syaifullah Ali, 2009, Karakteristik Marshall Campuran Hot Rolled Sheet (HRS) yang Mengandung Cangkang Kelapa Sawit Sebagai Agregat Kasar,Padang, Politeknik Negeri Padang.

Departemen Pekerjaan Umum, 2010, Spesifikasi Umum Bina Marga Divisi 6 Perkerasan Aspal.

Miftahul Fauziah dan Henri Febriansyah, 2013, Pemanfaatan Limbah Cangkang Kelapa Sawit Untuk Meningkatkan Kekuatan dan Keawetan Campuran Asphalt Concrete Binder Course (AC$B C)$, Yogyakarta, Universitas Islam Indonesia.
Rian Putrowijoyo, 2006, Kajian Laboratorium Sifat Marshall dan Durabilitas Asphalt Comcrete - Wearing Course (AC-WC) dengan Membandingkan Penggunaan Antara Semen Portland dan Abu Batu Sebagai Fille. Semarang, Universitas Diponegoro. 